Review Article

\title{
IFN- $\lambda$ : A New Class of Interferon with Distinct Functions-Implications for Hepatitis C Virus Research
}

\author{
Bing Liu, ${ }^{1}$ Ian McGilvray, ${ }^{1,2}$ and Limin Chen ${ }^{1,2}$ \\ ${ }^{1}$ Institute of Blood Transfusion, Chinese Academy of Medical Sciences, Peking Union Medical College, Chengdu, Sichuan 610052, China \\ ${ }^{2}$ Toronto General Research Institute, University Health Network, University of Toronto, Toronto, ON, Canada M5G IL6 \\ Correspondence should be addressed to Limin Chen; limin_chen_99@yahoo.com
}

Received 26 November 2014; Accepted 6 April 2015

Academic Editor: Anastasios Koulaouzidis

Copyright (c) 2015 Bing Liu et al. This is an open access article distributed under the Creative Commons Attribution License, which permits unrestricted use, distribution, and reproduction in any medium, provided the original work is properly cited.

\begin{abstract}
Pegylated interferon- $\alpha$ and ribavirin (PEG-IFN/RBV) is widely used to treat chronic hepatitis $C$ virus infection with notorious adverse reactions since the broad expression of IFN- $\alpha$ receptors on all nucleated cells. Accordingly, a Type III IFN with restricted receptors distribution is much safer as an alternative for HCV therapy. In addition, single nucleotide polymorphisms (SNPs) near the human $I F N-\lambda 3$ gene, $I L-28 B$, correlate strongly with the ability to achieve a sustained virological response (SVR) to therapy with pegylated IFN- $\alpha$ plus ribavirin in patients infected with chronic hepatitis C. Furthermore, we also discuss the most recent findings: IFN- $\lambda 4$ predicts treatment outcomes of HCV infection. In consideration of the apparent limitations of current $\mathrm{HCV}$ therapy, especially high failure rate and universal side effects, prediction of treatment outcomes prior to the initiation of treatment and developing new alternative drugs are two important goals in HCV research.
\end{abstract}

\section{Introduction}

More than 30 years ago, a blood-borne non-A, non-B hepatitis was discovered and the virus was subsequently named as hepatitis C virus (HCV) (Figure 1). Currently, an estimation of 130-170 million people are chronically infected with HCV worldwide, which is a growing global pandemic and financial burden to the society [1]. Current standard of care (SOC) is the combination therapy with pegylated IFN $-\alpha$ and ribavirin (PEG-IFN/RBV) in developing countries, while DAAs in combination with PEG-IFN/RBV (triple therapy) significantly improve the SVR to some extent in developed districts [2]. Nevertheless, in consideration of morbid side effects, variable cure rates, and high costs, it is very important to predict treatment response and identify critical insights into mechanism of viral resistance. In this review, we will discuss biology and signaling pathway of the IFN $-\lambda$ s, as well as their utility in clinic trial of anti-HCV therapy and link with treatment-induced clearance of $\mathrm{HCV}$ for prediction of treatment outcome.

\section{A Brief History of IFN- $\lambda$}

2.1. Classification. In 2003, the first 3 members of the IFN$\lambda$ family (IFN- $\lambda 1$, IFN- $\lambda 2$, and IFN- $\lambda 3$ ) were uncovered by
2 independent groups based on genomic sequence $[3,4]$. With the development of genome-wide association studies (GWAS), Prokunina-Olsson and his colleagues discovered a novel IFN- $\lambda$ gene, IFN- $\lambda$, which is located in between IFN$\lambda 2$ and IFN- $\lambda 3$ [5]. IFN- $\lambda 4$ is a low-level-expression protein in a small fraction of the human population which is different from other IFNs. Its expression depends on polymorphism ss469415590, which is in linkage disequilibrium (LD) with $r s 12979860$. IFN- $\lambda 4$ protein can only be produced by individuals who carry the $\Delta G$ allele of the $s s 469415590$ variant (IFN$\lambda 4-\Delta G$ ), while the major TT allele disrupts the IFN- $\lambda 4$ ORF due to a frame shift [6]. While being structurally related to IL10 -related cytokines, IFN- $\lambda$ s have been functionally classified as a distinct type of IFN because they signal through binding to IFN $\lambda$ receptor to exert the antiviral activity [7].

2.2. IFN- $\lambda$ Receptor Distribution. IFN- $\lambda$ s bind and signal through a heterodimer receptor composed of a short IL10R2 chain (also called IL-10Ra) and a long chain IL-28R1 (also called IL-28Ra) [3,4]. Although the short chain is ubiquitously expressed and is a primary part of the receptor complexes for IL-10, IL-22, and IL-26, the long chain is utilized only by IFN $\lambda$ and has a limited tissue distribution 


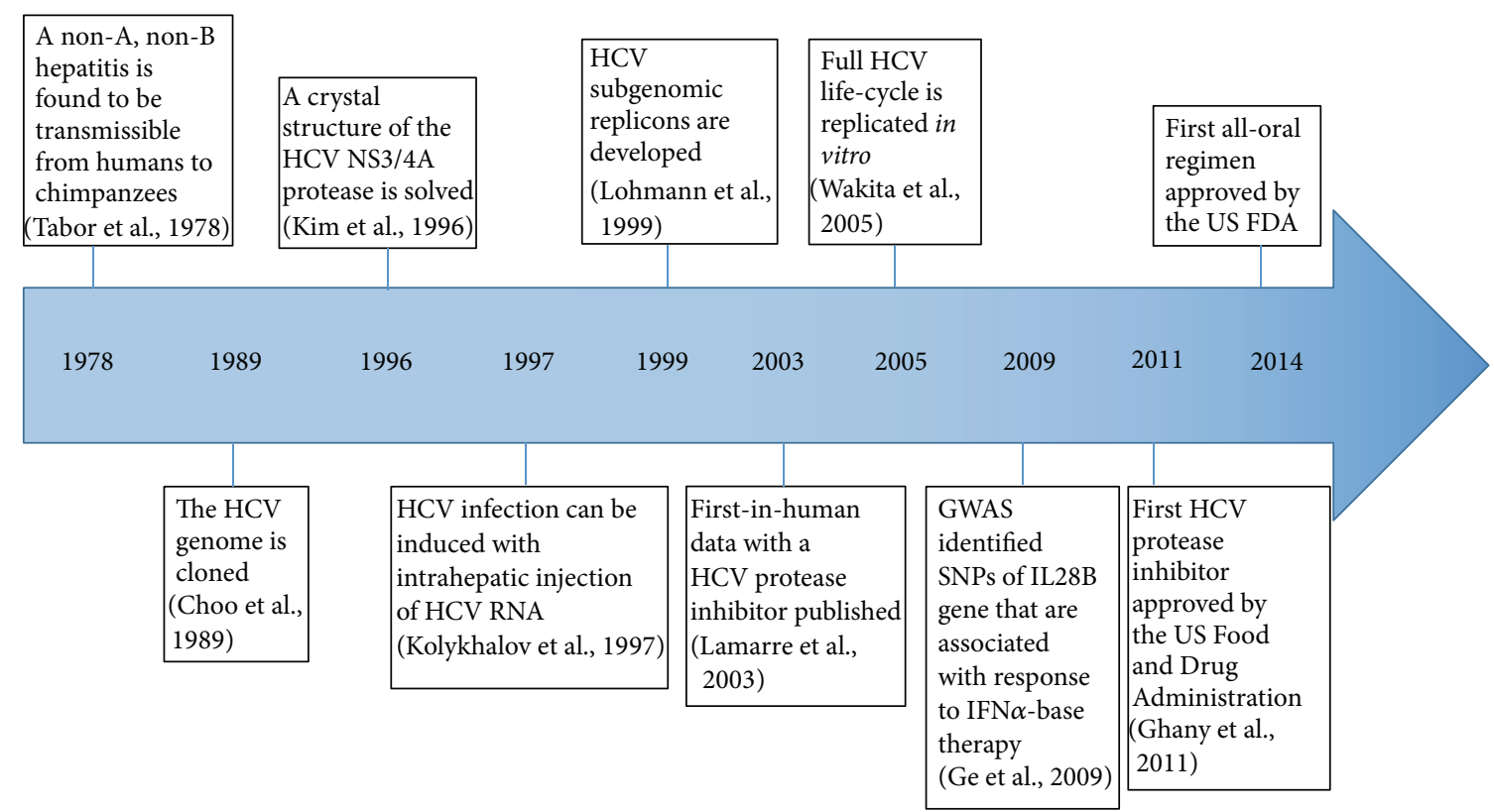

FIGURE 1: Timeline | Key discoveries in the basic science of HCV.

[8]. Broadly speaking, Type III IFNs are similar to Type I IFNs $($ IFN- $\alpha /$ IFN- $\beta$ ) in that they both have antiviral and immunomodulatory properties. On the other hand, they are quite different. While Type I IFNs (IFN- $\alpha /$ IFN- $\beta$ ) are ubiquitously expressed by most somatic cells, Type III IFNs can only be expressed by some cell types, such as epidermal, bronchial, and gastrointestinal epithelial cells [9]. In addition, IFN- $\lambda$ receptors are not found on fibroblasts [10], microvascular endothelial cells, adipocytes [8], or primary CNS cells [11]. IL-28R1 was shown to be expressed on the surface of some circulating immune cells including B cells, T cells, DCs $[12$, 13], and macrophages [14]. Nevertheless, these cells expressed a short IFN- $\lambda$ receptor splice variant (sIFN- $\lambda$ R1/sIL-28R1) to reveal a secreted, glycosylated protein to inhibit IFN- $\lambda$ signaling through binding IFN- $\lambda 1$ with a moderate affinity $\left(K_{D} 73 \mathrm{nM}\right)$ [8]. Therefore, there is no consensus conclusion about receptor levels on the surface of immune cells, which are an influential target of IFNs in general [15].

2.3. IFN- $\lambda$-Mediated Signaling Pathway. Although they signal through distinct receptors, Type I and Type III IFNs trigger remarkably similar responses in cells through activation of the Jak/STAT pathway (Figure 2). Viral nucleic acids are sensed by transmembrane Toll-like receptors (TLRs), cytoplasmic DNA sensors, and RNA helicases, resulting in the activation of kinases to initiate signaling cascade [16]. The kinases activate NF- $\kappa \mathrm{B}, \mathrm{IRF} 3$ and IRF7 transcription factors to induce their subsequent translocation into the nucleus where they promote IFN gene transcription [17]. The complex of IRF3 and NF- $\kappa \mathrm{B}$ stimulates expression of IFN- $\beta$ and IFN- $\lambda 1$, while the complex of IRF7 and NF- $\kappa \mathrm{B}$ stimulates the expression of IFN- $\alpha$ and IFN- $\lambda 2$ and IFN- $\lambda 3$ [18]. Once produced, Types I and III IFNs translocate from the nucleus to the cytomembrane to bind their receptors, respectively, to activate the overlapping Jak/STAT signaling pathway. Type I IFNs use a dimeric receptor (IFNAR) composed of subunits IFNAR1 and IFNAR2c, whereas Type III IFNs signal through a different receptor, which is composed of IL-28Ra and IL10Ra. After IFNs bind to their specific receptors, the receptor-associated tyrosine kinases, JAK1, TYK2, are activated to further simulate phosphorylation of STAT proteins. On the one hand, activated STAT1, STAT2, and IRF-9 form a heterotrimeric transcription factor complex called IFN-stimulated gene factor 3 (ISGF3). ISGF3 is then translocated into the nucleus where it binds to sequences of IFN-stimulated response elements (ISRE) present in the promoter region of numerous interferon stimulated genes (ISGs) [19]. On the other hand, a homodimer STAT1 (gamma interferon activation factor, GAF) is formed and translocated into the nucleus where it binds to GAS (gamma interferon activation site) to induce ISGs expression [20, 21]. The proteins encoded by these ISGs have different biological functions. Some mediate a myriad of antiviral activities, such as ISG15, MxA, and OAS. Several ISG-encode proteins like IRF7, IRF3 amplify IFNs production through a positive feedback [22]. Nevertheless, ISG-encoded proteins like USP18 and SOCS1 act as negative regulators for IFN signal pathway $[23,24]$.

\section{Clinical Applications of IFNs for HCV Treatment}

3.1. Current Treatment Regime for HCV Infection. With the development of recombinant IFNs, IFN- $\alpha$-based treatment has formed the cornerstone for the treatment of $\mathrm{HCV}$ infection for the past two decades [25]. Until now the standard of care (SOC) for HCV in most developing countries is weekly subcutaneous injection of pegylated IFN- $\alpha$ 


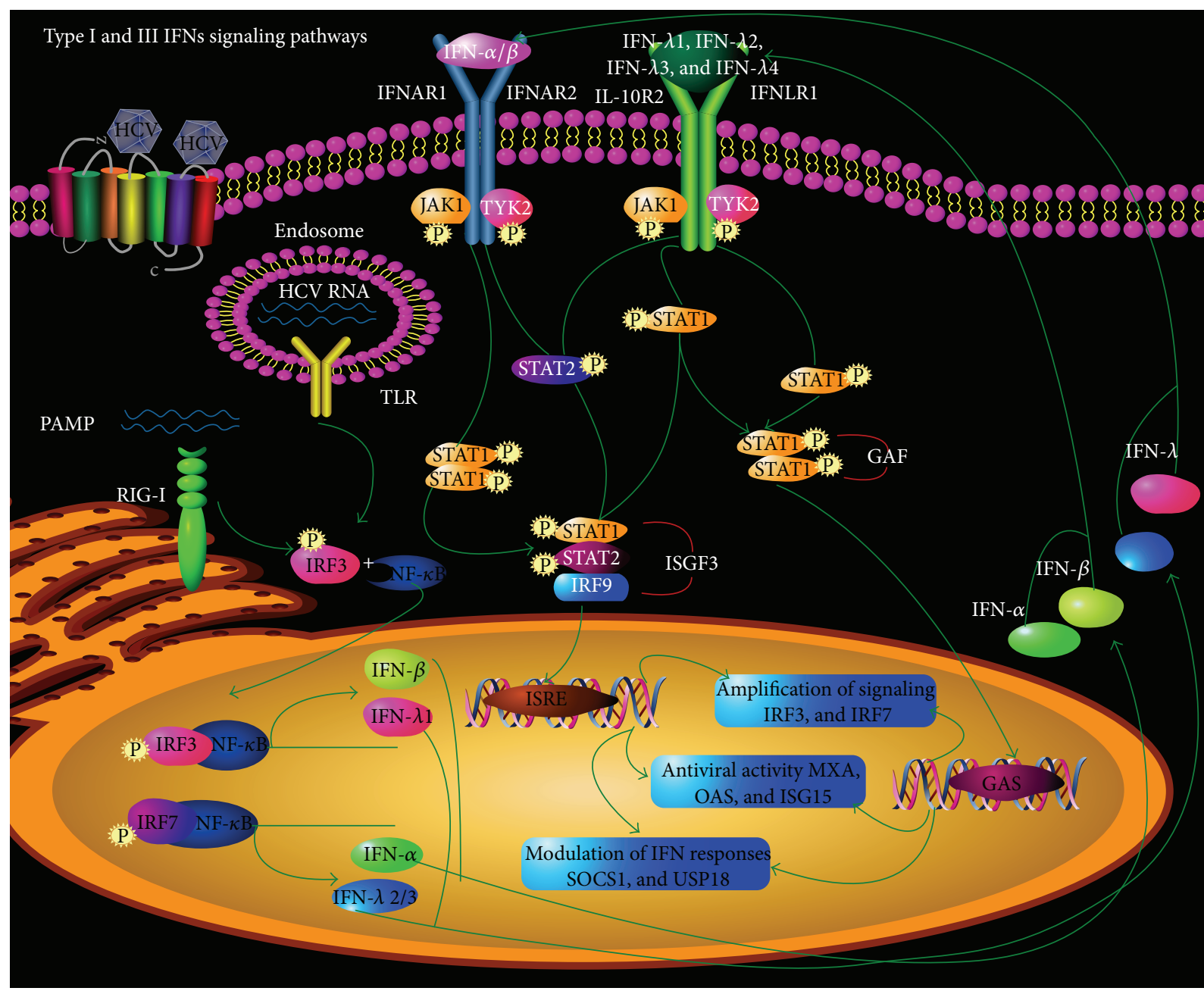

FIGURE 2: Types I and III IFNs canonical signaling pathways. Viruses, including HCV, are recognized by pattern recognition receptor (PRR), TLR3, and/or RIG-I-like receptor, leading to the activation of kinases. This in turn results in phosphorylation of IRF3 and IRF7 and activation of NF- $\kappa$ B. They translocate to nucleus to form heterodimers, respectively, which can catalyze transcription of IFN- $\alpha$, IFN- $\beta$, and IFN- $\lambda$ genes by binding to specific DNA sequences. Then, Types I and III IFNs move out of nucleus to bind to their specific receptors on the cell membrane and trigger an overlap pathway, Jak/STAT signaling pathway. Upon binding to their cognate receptors, Type I can phosphorylate both STAT1 and STAT2 to form ISGF3 that binds to ISRE in the promoter region of ISGs to upregulate their transcription and Type III IFN also can phosphorylate STAT1 to form a homodimer GAF and induce ISGs expression with GAS in the promoter region. A myriad of ISG products is not only antiviral factors but also participation in the signaling pathway in virtue of positive/negative feedback.

(PEG-IFN- $\alpha$ ) combined with daily ribavirin [26]. However, the traditional success of IFN- $\alpha$-based treatment has been challenged by suboptimal SVR rates in treatment resistant patients, cumbersome treatment regime, and deleterious side effects [4]. The recently successful developments of numerous well-tolerated oral agents that target viral proteins to interfere with viral replication and direct antiviral agents (DAAs) increase SVR in patients infected with HCV [27]. There are four major groups of DAAs: NS3/4A protease inhibitor (PIs), NS5B nucleoside polymerase inhibitors (NPIs), NS5B nonnucleoside polymerase inhibitors (NNPIs), and NS5A inhibitors [28]. In 2011, the first DAAs telaprevir and boceprevir were approved by FDA. Combined with PEG-IFN/ribavirin treatment, these DAAs significantly increased the SVR up to $80 \%$ for the most prevalent HCV genotype 1 infected patients although they had marginal improvement of SVR in other genotypes [29, 30]. Currently, several promising DAAs are already in clinical trials as a monotherapy to translate the dream of a pill to cure HCV into reality (reviewed in [31]). FDA approved first the monopill, Harvoni (ledipasvir and sofosbuvir), without combination of interferon or ribavirin to treat HCV genotype 1 infection in October 2014. Indeed, IFNfree regimen is beneficial for patients with poor tolerance to IFN and/or who have suffered from extensive side effects. Nevertheless, the apparent limitations of DAAs include low genetic barrier to resistance and high cost. As such, interferon will still be used to treat $\mathrm{HCV}$ infection in the immediate future, especially in most developing countries.

\subsection{Potential Clinical Application of IFN $\lambda$ for $H C V$. Despite} the availability of new DAAs, IFN-a-based treatment remains an effective therapy for HCV infection in most developing 
countries. However, in consideration of increasing viral resistance and undesirable systemic side effects due to the fact that virtually all cell types express IFNAR [32], other alternatives with better efficacy and less toxicity should be explored. As a consequence, IFN- $\lambda$ s, which trigger the overlapping Jak/STAT signaling pathway with IFN $\alpha$ through distinct IFN- $\lambda \mathrm{R} 1$ expressed only in restricted tissues [33], seem an ideal therapeutic candidate for HCV therapy. A more limited target cell range would be of great importance for the possible regimen applications of IFN- $\lambda$ s. Refractory state occurs commonly in cultured cells and in the liver through repeated stimulation with IFN- $\alpha$ [34], which is believed to be one of the reasons for nonresponse to the treatment with IFN- $\alpha$-based therapy in HCV-infected patients [35]. Surprisingly, IFN- $\lambda$ did not induce such a refractory state in liver cells [36]. That might be because tolerance of IFN$\alpha$-based therapy correlated with refractoriness of NK cells [37] where no expression of IFN- $\lambda \mathrm{R} 1$ was detected [38]. Although selective distribution of the IFN- $\lambda$ receptors would reduce the number of potential medical indications, fewer side effects would represent a big advantage over type I IFNs [39]. Preclinical studies showed that weekly PEG-IFN- $\lambda$ with or without daily RBV inhibited HCV replication in human hepatocytes with minimal adverse events and hematologic effects in patients with chronic HCV [40]. Furthermore, Muir and his group demonstrated that antiviral effects of recombinant IFN- $\lambda 1$ is comparable to recombinant IFN- $\alpha$ in clinical trial [41]. In recent phase 3 clinical trials, IFN$\lambda$ la was recommended as $180 \mathrm{mg}$ doses in combination with ribavirin and a direct-acting antiviral for 24-48 weeks in HCV genotype 1 or genotype 4 or 12-24 weeks in genotype 2 or genotype $3[42,43]$. Alternative treatment like IFN- $\lambda \mathrm{s}$ that target the host immune response with fewer side effects due to limited receptor distribution becomes a promising strategy.

\section{Prediction of Treatment Response in Patients Infected with Hepatitis C Virus}

Although some viral and host factors that are associated with viral clearance were identified, predication of response to therapy was suboptimal. It has been shown that host gene polymorphism plays an essential role in determining treatment outcomes of IFN- $\alpha$-based therapy. Ge and colleagues in 2009 discovered that single nucleotide polymorphisms (SNPs) linked to the IFN- $\lambda 3$ (also known as IL28B) was associated with the spontaneous and treatment-induced clearance of HCV infection [44]. Interestingly, patients with upregulation of ISGs in liver cells prior to receiving interferon treatment respond less well to interferon and are much more likely to have the unfavorable $I L-28 B$ genotype [ 45 , 46]. Furthermore, the polymorphism of new gene IFN$\lambda 4$ is strongly associated with impaired spontaneous HCV clearance, which serves as an important predictive biomarker for treatment outcomes $[47,48]$. Therefore, it is not surprising that IFN- $\lambda$ opened a new era for HCV therapy as well as for the prediction of treatment outcomes.

\section{Viral Factors to Predict IFN-based Treatment Response}

5.1. HCV Genotype. HCV contains six major genotypes (1-6) that differ from each other by $30-35 \%$ of nucleotide sequence [49]. Among the factors identified to influence treatment outcomes, viral genotype was recognized to be of major importance. Numerous studies indicated that the SVR of $80 \%$ for those infected with genotype 2 or genotype 3 are achieved, but $40-50 \%$ for patients infected with HCV genotype 1 or genotype 4 [50-52]. Thus, HCV-1 and HCV-4 are defined as difficult to treat genotypes. While with recent high-speed development of DAAs, the SVR of genotype 1 has been significantly increased [53]. Therefore, genotype 4 was the final piece of the puzzle to solve the problem. Although the key to the puzzle is unclear, it is indicated that dynamics of $\mathrm{HCV}$ genotype 4 are rather tardive, which are equal to those of HCV genotype 1 and slower than those of HCV genotype 2 [54]. In conclusion, genotype is one of the most significant viral factors in determining treatment outcomes of IFN- $\alpha$ based therapy.

5.2. Viral Load and Gene Mutations. This is paradoxical since a higher pretreatment viral load has been associated with a poor response to subsequent IFN- $\alpha$ treatment. Besides, it is well-known that the viral load reflects the intricate virushost interaction which can be affected by HCV genotypes. Thus, the pretreatment baseline and on-treatment viral load can be utilized to predict SVR. Currently, a rapid virological response (RVR) at week 4 of therapy has been identified as an important predictor of SVR in patients infected with $\mathrm{HCV}$ genotype 1 [55] or genotype 2 [56]. Meanwhile, more studies are looking for much earlier viral response after initiation of therapy to predict SVR [57], and even a prediction model was used [58].

In addition, HCV gene mutations also contribute to treatment response, of which the hot spot of mutation was focused on viral nonstructural protein 5A (NS5A). At least 3 functional domains of NS5A were involved in IFN resistance: ISDR (Interferon Sensitivity-Determining Region), PKRBD (PKR Binding Domain), and V3 (Variable region 3) at the $\mathrm{C}$ terminus [59]. Enomoto et al. further demonstrated that 4 or more mutations in the NS5A region (known as "mutant type") were associated with high SVR rate in Japanese patients chronically infected with HCV genotype $1 b$ [60]. There is still a subject of long controversy among different research groups $[61,62]$. Although the core region of $\mathrm{HCV}$ is conserved, mutations of amino acid (aa) 70 and aa 91 affected SVR rate $[63,64]$. However, the predictive effect of mutations in the HCV core region was only observed in HCV genotype $\mathrm{lb}$ and this prediction ability still remained elusive in other genotypes and subtypes.

\section{Host Factors to Predict IFN-Based Treatment Response}

6.1. Pretreatment ISG Expression Levels in the Liver and Blood. IFN $\alpha$ and IFN $\lambda$ ultimately play their roles through 
the upregulation of ISGs. It has been shown that cultured cells enter an IFN-desensitized state that can last up to several days shortly after IFN exposure because ISGs expression is already maximally stimulated and is therefore unresponsive to further exogenous IFN- $\alpha$ treatment [65]. Therefore, the expression level of ISGs in pretreatment liver or blood seems to be useful for prediction of treatment outcomes in patients with HCV. Indeed, it has been repeatedly demonstrated that a poor response to exogenous IFN- $\alpha$ treatment is associated with a higher intrahepatic ISGs expression before treatment [66-68]. Furthermore, with the development of microarray gene-expression profiling, a high throughput method that allows simultaneously examine gene expression at the transcript (mRNA) level, it is much easier to assess the host response to $\mathrm{HCV}$ infection at the whole genomic scale [68]. By comparing the pretreatment hepatic gene expression levels between treatment responders and nonresponders of patients chronically infected with HCV, Chen et al. [46, 69] identified 18 genes (out of 19,000 host genes or transcripts), whose differential expression levels are associated with treatment outcomes. More interestingly, they further demonstrated that the cell-type specific expression of ISGs was correlated well with treatment outcomes, with prediction accuracy higher than that predicted by the polymorphism of IL-28B [70, 71].

Although correlation between increased pretreatment ISGs expression in liver and failure of anti-HCV therapy was identified, it is necessary to develop an easier noninvasive predictive test. In addition to the liver tissue, numerous researches revealed that blood samples might be a perfect alternative $[72,73]$. Rallon et al. demonstrated that assessment of HCV/HIV coinfected patients with PEG-IFN/RBV therapy in that PBMC specimens can reliably be used for evaluating ISGs expression in clinical regardless of IL-28B genotypes [74]. In addition, wide application of DAAs urges us to develop a predictive biomarker to predict treatment outcomes in order to save expensive cost of DAAs therapy. Meissner et al. [75] conducted a clinical trial using the DAA sofosbuvir plus ribavirin (SOF/RBV) and performed detailed mRNA expression analysis in liver and peripheral blood from 60 patients who achieved either a sustained virologic response (SVR) or relapsed. They found that viral clearance was associated with rapid downregulation of IFN-stimulated genes (ISGs) in liver and blood, whereas the exact association between the expression level of ISGs in pretreatment and response to DAAs therapy would not be identified without more clinic trails.

6.2. Host Interleukin-28B (IL-28B) Genotype and SVR. Over the last decade, a myriad of host factors have been shown to play an important role in predicting the clinical outcomes of HCV by virtue of in-depth understanding of human genome and technology progress such as microarray and genomewide association studies (GWAS). These studies accessed common SNPs among the host genome by means of a disease library, such as patients and healthy volunteers, without hypothesis based on background knowledge. Therefore, they independently uncovered the influence of $I L-28 B$ SNP on treatment-induced and spontaneous HCV clearance. The first landmark research facilitated by GWAS was published in
2009 [44]. Ge's group assessed the treatment outcome in a group of $1671 \mathrm{HCV}$ genotype 1 patients with treatment of injecting PEG-IFN/RBV. There was a significant association between SVR and $I L-28 B$, rs 12979860 SNP. Patients with allele $(C / C)$ had rather higher SVR rate $(78 \%)$ than those with allele $(T / T)(28 \%)$ as well as heterozygote gene $(T / C)(38 \%)$. In addition, they further compared the efficacy of PEGIFN/RBV treatment in association with $I L-28 B$ genotype in different ethnicity. They concluded that more favorable IL28B genotype was found in European than African populations, which explain higher SVR in European-Americans to some extent. However, compared with factors associated with viral clearance, host $I F N-\lambda 3$ genotype was more important than baseline viral load, the degree of liver fibrosis, or ethnicity. In subsequent years, different researches drew consistent conclusion that SNPs of $I L-28 B$ is strongly associated with $\mathrm{HCV}$ treatment outcomes [76, 77]. In addition, the verdict was extended to both HCV monoinfected and HCV/HIV coinfected populations. They revealed that the minor allele of $R s 8099917$ was identified in 58\% of patients who did not respond to treatment and defined as a risk factor related to progression to chronic $\mathrm{HCV}$ infection, regardless of the coinfection with HIV or not [78].

6.3. IFN- $\lambda 4$ Genetic Variation and Response to Treatment. Recently, a new variant of $I F N-\lambda 4$, denoted as $s s 469415590$ $(T T / \Delta G)$ has been discovered, whose $\Delta G$ allele is strongly associated with impaired spontaneous HCV clearance as a result of high expression of IL-28B [47]. Interestingly, $\Delta G$ allele of $s s 469415590$ expressed a novel IFN- $\lambda 4$, which could block the activity of Types I and III IFNs, decreasing the capacity of HCV clearance [79]. However, the mechanism of its negative regulation of IFNs signaling pathway was elusive. Considering poorly expression and antiviral activity of IFN- $\lambda 4$, impeding receptor binding of other members of the IFN- $\lambda$ family is a possible explanation [80]. In any event, ss469415590 sounds like a better predictor of SVR than the traditional $r s 12979860$. However, the predictive effect of $s s 469415590$ is still controversial (Table 1). Therefore, although the sensitivity, specificity, and predictive value of them currently identified are too low to be clinically useful alone, these studies confirmed a significant association between $I F N-\lambda 4$ genetic variation and response to treatment. Further studies should be done to explore the mechanism underlying this close association.

\section{Prospective}

Currently, there is no vaccine for $\mathrm{HCV}$ infection and the SOC is PEG-IFN/RBV in most developing countries. With the ever-increasing number of DAAs in development and the amazing rate of SVR reported, the era of interferon as a hallmark therapy for HCV is apparently nearing its end in developed districts regardless of the astounding cost. In contrast, despite morbid side effects and variable cure rates, IFN- $\alpha$ based treatment is still a dominant therapy in most developing countries due to cost containment. In addition, it is necessary to understand molecular mechanisms of virushost interactions and to predict treatment outcomes before 
TABLE 1: Genetic association studies of IFN- $\lambda 4$ and treatment outcomes.

\begin{tabular}{|c|c|c|c|}
\hline Single nucleotide & Subjects & Conclusions & Reference \\
\hline $\begin{array}{l}\text { ss } 469415590 \text { and } \\
r s 12979860\end{array}$ & $\begin{array}{l}169 \text { African-American } \\
\text { patients HCV-1 }\end{array}$ & $\begin{array}{l}\text { Compared to } r s 12979860, s s 469415590 \text { is more strongly } \\
\text { associated with HCV clearance in individuals of } \\
\text { African ancestry rather than in Europeans and Asians }\end{array}$ & {$[5]$} \\
\hline $\begin{array}{l}\text { ss } 469415590 \text { and } \\
r s 12979860\end{array}$ & $\begin{array}{l}272 \text { Caucasian patients } \\
\text { HCV-1/HCV-4 }\end{array}$ & $\begin{array}{l}\text { The } s s 469415590 \text { variant shows an equivalent } \\
\text { performance to predict SVR to pegIFN/RBV with } \\
\text { rs12979860 }\end{array}$ & {$[81]$} \\
\hline ss469415590 & $\begin{array}{l}80 \mathrm{HCV} \text { patients and } 78 \\
\text { liver donors }\end{array}$ & $\begin{array}{l}\text { lower expression of IFN- } \lambda 4 \text { mRNA was associated with } \\
\text { a higher rate of SVR in response to pegIFN- } \alpha \text { and } \\
\text { ribavirin therapy }\end{array}$ & {$[82]$} \\
\hline rs 12979860 & $\begin{array}{l}362 \mathrm{HCV}-1 \text { patients in a } \\
\text { phase } 2 \mathrm{~b} \text { trial of faldaprevir } \\
\text { and deleobuvir }\end{array}$ & $\begin{array}{l}\text { SVR in response to faldaprevir and deleobuvir was } \\
\text { lower in the patients with the CT or TT genotypes for } \\
I F N-\lambda 4 \text { rs } 12979860\end{array}$ & {$[83]$} \\
\hline $\begin{array}{l}\text { ss } 469415590 \text { and } \\
\text { rs12979860 }\end{array}$ & $\begin{array}{l}207 \text { HCV/HIV-1 coinfected } \\
\text { patients treated with } \\
\text { PEG-IFN/RBV therapy } \\
\end{array}$ & $\begin{array}{l}\text { ss } 469415590 \text { genotype was a better predictor of } \\
\text { treatment failure than } r s 12979860\end{array}$ & {$[84]$} \\
\hline $\begin{array}{l}\text { ss469415590, } r s 8099917, \\
r s 12979860 \text { and } r s 12980275\end{array}$ & $\begin{array}{l}280 \mathrm{HCV} \text { patients treated } \\
\text { with PEG-IFN/RBV }\end{array}$ & $\begin{array}{l}s s 469415590 \text { is superior to other } I L-28 B \text { variants } \\
\text { especially in patients with advanced fibrosis }\end{array}$ & [85] \\
\hline $\begin{array}{l}\text { ss } 469415590 \text { and } \\
r s 12979860\end{array}$ & $\begin{array}{l}225 \text { Thai } \\
\text { HCV-1/HCV-3/HCV-6 } \\
\text { patients treated with } \\
\text { PEG-IFN/RBV }\end{array}$ & $\begin{array}{l}I F N-\lambda 3 \text { (IL28B) and } I F N-\lambda 4 \text { polymorphisms are } \\
\text { associated with treatment response in Thai patients } \\
\text { infected with HCV genotype } 1 \text {, but not with genotypes } 3 \\
\text { and } 6\end{array}$ & {$[86]$} \\
\hline rs12979860 & $\begin{array}{l}115 \mathrm{HCV}-1 \text { patients treated } \\
\text { with sofosbuvir }\end{array}$ & $\begin{array}{l}\text { The IFN- } \lambda 4-\Delta G \text { allele was associated with slower early } \\
\text { viral decay }\end{array}$ & {$[75]$} \\
\hline
\end{tabular}

initiating therapy. Further studies need to be focused on an overall pattern taking both viral and host factors into account, which may be more reliable to predict HCV treatment response rather than one or two independent predictors. As a consequence, it is not surprising that IFN- $\lambda$ s opened a new era as an ideal alternative for IFN- $\alpha$ with less side effects and viral resistance as well as for prediction of treatment outcomes.

\section{Conflict of Interests}

The authors declare that there is no conflict of interests regarding the publication of this paper.

\section{Acknowledgments}

This study was partially supported by Grants from Natural Science Foundation of China (NSFC, 81471956, 91442128) and 2013SZ0066 to Dr. J. Yuan/Dr. L. Chen through Sichuan Mingri Pharmaceutical Research Institute of New Technology.

\section{References}

[1] M. F. Sorrell, E. A. Belongia, J. Costa et al., "National Institutes of Health consensus development conference statement: management of hepatitis B," Hepatology, vol. 49, no. 5, pp. S4-S12, 2009.

[2] J. J. Feld, "The beginning of the end: what is the future of interferon therapy for chronic hepatitis C?" Antiviral Research, vol. 105, pp. 32-38, 2014.
[3] P. Sheppard, W. Kindsvogel, W. Xu et al., "IL-28, IL-29 and their class II cytokine receptor IL-28R," Nature Immunology, vol. 4, no. 1, pp. 63-68, 2003.

[4] S. V. Kotenko, G. Gallagher, V. V. Baurin et al., "IFN- $\lambda$ s mediate antiviral protection through a distinct class II cytokine receptor complex," Nature Immunology, vol. 4, no. 1, pp. 69-77, 2003.

[5] L. Prokunina-Olsson, B. Muchmore, W. Tang et al., "A variant upstream of IFNL3 (IL28B) creating a new interferon gene IFNL4 is associated with impaired clearance of hepatitis C virus," Nature Genetics, vol. 45, no. 2, pp. 164-171, 2013.

[6] T. R. O'Brien, L. Prokunina-Olsson, and R. P. Donnelly, "IFN$\lambda 4$ : the paradoxical new member of the interferon lambda family," Journal of Interferon \& Cytokine Research, vol. 34, no. 11, pp. 829-838, 2014.

[7] C. Kelly, P. Klenerman, and E. Barnes, "Interferon lambdas: the next cytokine storm," Gut, vol. 60, no. 9, pp. 1284-1293, 2011.

[8] K. Witte, G. Gruetz, H.-D. Volk et al., "Despite IFN- $\lambda$ receptor expression, blood immune cells, but not keratinocytes or melanocytes, have an impaired response to type III interferons: Implications for therapeutic applications of these cytokines," Genes \& Immunity, vol. 10, no. 8, pp. 702-714, 2009.

[9] C. Sommereyns, S. Paul, P. Staeheli et al., "IFN-Lambda (IFN$\lambda$ ) is expressed in a tissue-dependent fashion and primarily acts on epithelial cells in vivo," PLoS Pathogens, vol. 4, no. 3, Article ID e1000017, 2008.

[10] A. Meager, K. Visvalingam, P. Dilger, D. Bryan, and M. Wadhwa, "Biological activity of interleukins-28 and -29: comparison with type I interferons," Cytokine, vol. 31, no. 2, pp. 109-118, 2005.

[11] N. E. Pagliaccetti and M. D. Robek, "Interferon- $\lambda$ in the immune response to hepatitis B virus and hepatitis C virus," Journal of Interferon \& Cytokine Research, vol. 30, no. 8, pp. 585-590, 2010.

[12] K. Wolk, K. Witte, E. Witte et al., "Maturing dendritic cells are an important source of IL-29 and IL-20 that may cooperatively 
increase the innate immunity of keratinocytes," Journal of Leukocyte Biology, vol. 83, no. 5, pp. 1181-1193, 2008.

[13] S. Marukian, L. Andrus, T. P. Sheahan et al., "Hepatitis C virus induces interferon- $\lambda$ and interferon-stimulated genes in primary liver cultures," Hepatology, vol. 54, no. 6, pp. 1913-1923, 2011.

[14] F. J. D. Mennechet and G. Uzé, "Interferon- $\lambda$-treated dendritic cells specifically induce proliferation of FOXP3-expressing suppressor T cells," Blood, vol. 107, no. 11, pp. 4417-4423, 2006.

[15] S. E. Doyle, H. Schreckhise, K. Khuu-Duong et al., "Interleukin29 uses a type 1 interferon-like program to promote antiviral responses in human hepatocytes," Hepatology, vol. 44, no. 4, pp. 896-906, 2006.

[16] K. Onoguchi, M. Yoneyama, A. Takemura et al., "Viral infections activate types I and III interferon genes through a common mechanism," The Journal of Biological Chemistry, vol. 282, no. 10, pp. 7576-7581, 2007.

[17] Z. Makowska and M. H. Heim, "Interferon signaling in the liver during hepatitis C virus infection," Cytokine, vol. 59, no. 3, pp. 460-466, 2012.

[18] P. I. Österlund, T. E. Pietilä, V. Veckman, S. V. Kotenko, and I. Julkunen, "IFN regulatory factor family members differentially regulate the expression of type III IFN (IFN- $\lambda$ ) genes," The Journal of Immunology, vol. 179, no. 6, pp. 3434-3442, 2007.

[19] S. M. Horner and M. Gale Jr., "Regulation of hepatic innate immunity by hepatitis C virus," Nature Medicine, vol. 19, no. 7, pp. 879-888, 2013.

[20] J. Wu and Z. J. Chen, "Innate immune sensing and signaling of cytosolic nucleic acids," Annual Review of Immunology, vol. 32, no. 1, pp. 461-488, 2014.

[21] M. H. Heim, "Innate immunity and HCV," Journal of Hepatology, vol. 58, no. 3, pp. 564-574, 2013.

[22] N. Jilg, W. Lin, J. Hong et al., "Kinetic differences in the induction of interferon stimulated genes by interferon- $\alpha$ and interleukin $28 \mathrm{~B}$ are altered by infection with hepatitis C virus," Hepatology, vol. 59, no. 4, pp. 1250-1261, 2014.

[23] R.-X. Shao, L. Zhang, Z. Hong et al., "SOCS1 abrogates IFN's antiviral effect on hepatitis C virus replication," Antiviral Research, vol. 97, no. 2, pp. 101-107, 2013.

[24] V. François-Newton, G. M. de Freitas Almeida, B. PayelleBrogard et al., "USP18-based negative feedback control is induced by type I and type III interferons and specifically inactivates interferon $\alpha$ response," PLoS ONE, vol. 6, no. 7, Article ID e22200, 2011.

[25] C. Koh and T. J. Liang, "What is the future of ribavirin therapy for hepatitis C?" Antiviral Research, vol. 104, no. 1, pp. 34-39, 2014.

[26] M. Sarasin-Filipowicz, "Interferon therapy of hepatitis C: molecular insights into success and failure," Swiss Medical Weekly, vol. 140, no. 1-2, pp. 3-11, 2010.

[27] J. J. Feld and J. H. Hoofnagle, "Mechanism of action of interferon and ribavirin in treatment of hepatitis C," Nature, vol. 436, no. 7053, pp. 967-972, 2005.

[28] F. Lin and H. A. Young, "Interferons: success in anti-viral immunotherapy," Cytokine \& Growth Factor Reviews, vol. 25, no. 4, pp. 369-376, 2014.

[29] K. E. Sherman, S. L. Flamm, N. H. Afdhal et al., "Responseguided telaprevir combination treatment for hepatitis $\mathrm{C}$ virus infection," The New England Journal of Medicine, vol. 365, no. 11, pp. 1014-1024, 2011.
[30] S. Zeuzem, P. Andreone, S. Pol et al., "Telaprevir for retreatment of HCV infection," The New England Journal of Medicine, vol. 364 , no. 25, pp. 2417-2428, 2011.

[31] J. Jaroszewicz, R. Flisiak, and G. Dusheiko, "A pill for HCVmyth or foreseeable future?" Liver International, vol. 34, no. 1, pp. 6-11, 2014.

[32] Z. Zhou, O. J. Hamming, N. Ank, S. R. Paludan, A. L. Nielsen, and R. Hartmann, "Type III interferon (IFN) induces a type I IFN-like response in a restricted subset of cells through signaling pathways involving both the Jak-STAT pathway and the mitogen-activated protein kinases," Journal of Virology, vol. 81, no. 14, pp. 7749-7758, 2007.

[33] J. Pott, T. Mahlakõiv, M. Mordstein et al., "IFN- $\lambda$ determines the intestinal epithelial antiviral host defense," Proceedings of the National Academy of Sciences of the United States of America, vol. 108, no. 19, pp. 7944-7949, 2011.

[34] M. Sarasin-Filipowicz, X. Wang, M. Yan et al., "Alpha interferon induces long-lasting refractoriness of JAK-STAT signaling in the mouse liver through induction of USP18/UBP43," Molecular and Cellular Biology, vol. 29, no. 17, pp. 4841-4851, 2009.

[35] H. Qashqari, A. Al-Mars, A. Chaudhary et al., "Understanding the molecular mechanism(s) of hepatitis $\mathrm{C}$ virus (HCV) induced interferon resistance," Infection, Genetics and Evolution, vol. 19, pp. 113-119, 2013.

[36] Z. Makowska, F. H. T. Duong, G. Trincucci, D. F. Tough, and M. H. Heim, "Interferon- $\beta$ and interferon- $\lambda$ signaling is not affected by interferon-induced refractoriness to interferon- $\alpha$ in vivo," Hepatology, vol. 53, no. 4, pp. 1171-1180, 2011.

[37] B. Edlich, G. Ahlenstiel, A. A. Zabaleta et al., "Early changes in interferon signaling define natural killer cell response and refractoriness to interferon-based therapy of hepatitis $\mathrm{C}$ patients," Hepatology, vol. 55, no. 1, pp. 39-48, 2012.

[38] Z. Yin, J. Dai, J. Deng et al., “Type III IFNs are produced by and stimulate human plasmacytoid dendritic cells," The Journal of Immunology, vol. 189, no. 6, pp. 2735-2745, 2012.

[39] D. Olagnier and J. Hiscott, "Type I and type III interferoninduced immune response: it's a matter of kinetics and magnitude," Hepatology, vol. 59, no. 4, pp. 1225-1228, 2014.

[40] E. L. Ramos, "Preclinical and clinical development of pegylated interferon-lambda 1 in chronic hepatitis C," Journal of Interferon and Cytokine Research, vol. 30, no. 8, pp. 591-595, 2010.

[41] A. J. Muir, M. L. Shiffman, A. Zaman et al., "Phase 1b study of pegylated interferon lambda 1 with or without ribavirin in patients with chronic genotype 1 hepatitis C virus infection," Hepatology, vol. 52, no. 3, pp. 822-832, 2010.

[42] X. Wang, M. Hruska, P. Chan et al., "Derivation of Phase 3 dosing for peginterferon lambda-1a in chronic hepatitis C, Part 1: modeling optimal treatment duration and sustained virologic response rates," The Journal of Clinical Pharmacology, vol. 55, no. 1, pp. 63-72, 2015.

[43] M. Hruska, X. Wang, P. Chan et al., "Derivation of Phase 3 dosing for peginterferon lambda-1a in chronic hepatitis C, Part 2: exposure-response analyses for efficacy and safety variables," The Journal of Clinical Pharmacology, vol. 55, no. 1, pp. 73-80, 2015.

[44] D. Ge, J. Fellay, A. J. Thompson et al., "Genetic variation in IL28B predicts hepatitis C treatment-induced viral clearance," Nature, vol. 461, no. 7262, pp. 399-401, 2009.

[45] I. McGilvray, J. J. Feld, L. Chen et al., "Hepatic cell-type specific gene expression better predicts HCV treatment outcome than IL28B genotype," Gastroenterology, vol. 142, no. 5, pp. 1122.e11131.e1, 2012. 
[46] B. I. Chen L, J. Sun, M. Guindi et al., "Cell-type specific gene expression signature in liver underlies response to interferon therapy in chronic hepatitis C infection," Gastroenterology, vol. 138, no. 3, pp. 1123-1133, 2010.

[47] P. V. Aka, M. H. Kuniholm, R. M. Pfeiffer et al., "Association of the IFNL4- $\Delta \mathrm{G}$ allele with impaired spontaneous clearance of hepatitis C virus," Journal of Infectious Diseases, vol. 209, no. 3, pp. 350-354, 2014.

[48] Y. Nagaoki, M. Imamura, Y. Kawakami et al., "Interferon lambda 4 polymorphism affects on outcome of telaprevir, pegylated interferon and ribavirin combination therapy for chronic hepatitis C," Hepatology Research, vol. 44, no. 14, pp. E447-E454, 2014.

[49] P. Simmonds, J. Bukh, C. Combet et al., "Consensus proposals for a unified system of nomenclature of hepatitis $\mathrm{C}$ virus genotypes," Hepatology, vol. 42, no. 4, pp. 962-973, 2005.

[50] B. L. Pearlman and N. Traub, "Sustained virologic response to antiviral therapy for chronic hepatitis $\mathrm{C}$ virus infection: a cure and so much more," Clinical Infectious Diseases, vol. 52, no. 7, pp. 889-900, 2011.

[51] M. G. Ghany, D. B. Strader, D. L. Thomas, and L. B. Seeff, "Diagnosis, management, and treatment of hepatitis C: an update," Hepatology, vol. 49, no. 4, pp. 1335-1374, 2009.

[52] M. W. Fried, M. L. Shiffman, K. R. Reddy et al., "Peginterferon alfa-2a plus ribavirin for chronic hepatitis $\mathrm{C}$ virus infection," The New England Journal of Medicine, vol. 347, no. 13, pp. 975-982, 2002.

[53] C. Sarrazin, C. Hézode, S. Zeuzem, and J.-M. Pawlotsky, "Antiviral strategies in hepatitis C virus infection," Journal of Hepatology, vol. 56, supplement 1, pp. S88-S100, 2012.

[54] P. Halfon, A. U. Neumann, M. Bourlière et al., "Slow viral dynamics of hepatitis C virus genotype 4," Journal of Viral Hepatitis, vol. 10, no. 5, pp. 351-353, 2003.

[55] H. Toyoda, T. Kumada, N. Shimada et al., "Baseline factors and early viral response (week 4) to antiviral therapy with peginterferon and ribavirin for predicting sustained virologic response in patients infected with hepatitis $C$ virus genotype 1 : a multicenter study," Journal of Medical Virology, vol. 85, no. 1, pp. 65-70, 2013.

[56] M. W. Fried, S. J. Hadziyannis, M. L. Shiffman, D. Messinger, and S. Zeuzem, "Rapid virological response is the most important predictor of sustained virological response across genotypes in patients with chronic hepatitis C virus infection," Journal of Hepatology, vol. 55, no. 1, pp. 69-75, 2011.

[57] Y. Wada, H. Tamai, A. Uno et al., "Prediction of efficacy to pegylated interferon- $\alpha-2 b$ plus ribavirin in patients with genotype 2 hepatitis $C$ virus using viral response within 2 weeks," Hepatology Research, vol. 44, no. 2, pp. 179-186, 2014.

[58] J. Itakura, Y. Asahina, N. Tamaki et al., "Changes in hepatitis C viral load during first 14 days can predict the undetectable time point of serum viral load by pegylated interferon and ribavirin therapy," Hepatology Research, vol. 41, no. 3, pp. 217-224, 2011.

[59] O. Stambouli, Hepatitis C Virus: Molecular Pathways and Treatments, 2014.

[60] N. Enomoto, I. Sakuma, Y. Asahina et al., "Comparison of fulllength sequences of interferon-sensitive and resistant hepatitis $\mathrm{C}$ virus $1 \mathrm{~b}$ : sensitivity to interferon is conferred by amino acid substitutions in the NS5A region," The Journal of Clinical Investigation, vol. 96, no. 1, pp. 224-230, 1995.

[61] K. Hayashi, Y. Katano, M. Ishigami et al., "Mutations in the core and NS5A region of hepatitis $\mathrm{C}$ virus genotype $1 \mathrm{~b}$ and correlation with response to pegylated-interferon-alpha $2 \mathrm{~b}$ and ribavirin combination therapy," Journal of Viral Hepatitis, vol. 18, no. 4, pp. 280-286, 2011.

[62] P. M. de Rueda, J. Casado, R. Patón et al., "Mutations in E2PePHD, NS5A-PKRBD, NS5A-ISDR, and NS5A-V3 of hepatitis $C$ virus genotype 1 and their relationships to pegylated interferon-ribavirin treatment responses," Journal of Virology, vol. 82, no. 13, pp. 6644-6653, 2008.

[63] S. Kitamura, M. Tsuge, T. Hatakeyama et al., "Amino acid substitutions in core and NS5A regions of the HCV genome can predict virological decrease with pegylated interferon plus ribavirin therapy," Antiviral Therapy, vol. 15, no. 8, pp. 1087-1097, 2010.

[64] R. Kozuka, M. Enomoto, H. Hai et al., "Changes in sequences of core region, interferon sensitivity-determining region and interferon and ribavirin resistance-determining region of hepatitis $\mathrm{C}$ virus genotype 1 during interferon-alpha and ribavirin therapy, and efficacy of retreatment," Hepatology Research, vol. 42, no. 12, pp. 1157-1167, 2012.

[65] S. Sakamoto, J. Qin, A. Navarro et al., "Cells previously desensitized to type 1 interferons display different mechanisms of activation of stat-dependent gene expression from naïve cells," The Journal of Biological Chemistry, vol. 279, no. 5, pp. 32453253, 2004.

[66] G. C. MacQuillan, W. B. de Boer, M. A. Platten et al., "Intrahepatic MxA and PKR protein expression in chronic hepatitis C virus infection," Journal of Medical Virology, vol. 68, no. 2, pp. 197-205, 2002.

[67] T. Asselah, I. Bieche, S. Narguet et al., "Liver gene expression signature to predict response to pegylated interferon plus ribavirin combination therapy in patients with chronic hepatitis C," Gut, vol. 57, no. 4, pp. 516-523, 2008.

[68] J. Hou, G. van Oord, Z. M. A. Groothuismink et al., "Gene expression profiling to predict and assess the consequences of therapy-induced virus eradication in chronic hepatitis $\mathrm{C}$ virus infection," Journal of Virology, vol. 88, no. 21, pp. 12254-12264, 2014.

[69] L. Chen, I. Borozan, J. Feld et al., "Hepatic gene expression discriminates responders and nonresponders in treatment of chronic hepatitis C viral infection," Gastroenterology, vol. 128, no. 5, pp. 1437-1444, 2005.

[70] Y. Zhu, B. Qin, C. Xiao, X. Lu, and L. Chen, "Cell-type specific interferon stimulated gene staining in liver underlies response to interferon therapy in chronic hbv infected patients," Digestive Diseases and Sciences, vol. 57, no. 9, pp. 2355-2361, 2012.

[71] G. Randall, L. Chen, M. Panis et al., "Silencing of USP18 potentiates the antiviral activity of interferon against hepatitis $\mathrm{C}$ virus infection," Gastroenterology, vol. 131, no. 5, pp. 1584-1591, 2006.

[72] M. Sarasin-Filipowicz, E. J. Oakeley, F. H. T. Duong et al., "Interferon signaling and treatment outcome in chronic hepatitis C," Proceedings of the National Academy of Sciences of the United States of America, vol. 105, no. 19, pp. 7034-7039, 2008.

[73] T. Huang, K. Tu, Y. Shyr, C.-C. Wei, L. Xie, and Y.-X. Li, “The prediction of interferon treatment effects based on time series microarray gene expression profiles," Journal of Translational Medicine, vol. 6, no. 1, article 44, 2008.

[74] N. I. Rallon, L. A. Lopez-Fernandez, M. I. Garcia et al., "Interferon-stimulated genes are associated with peginterferon/ribavirin treatment response regardless of IL28B alleles in hepatitis C virus/HIV-coinfected patients," AIDS, vol. 27, no. 5, pp. 687-696, 2013. 
[75] E. G. Meissner, D. Bon, L. Prokunina-Olsson et al., "IFNL4- $\Delta$ G genotype is associated with slower viral clearance in Hepatitis C, genotype-1 patients treated with sofosbuvir and ribavirin," Journal of Infectious Diseases, vol. 209, no. 11, pp. 1700-1704, 2014.

[76] V. Suppiah, M. Moldovan, G. Ahlenstiel et al., "IL28B is associated with response to chronic hepatitis $\mathrm{C}$ interferon- $\alpha$ and ribavirin therapy," Nature Genetics, vol. 41, no. 10, pp. 1100-1104, 2009.

[77] Y. Tanaka, N. Nishida, M. Sugiyama et al., "Genome-wide association of IL28B with response to pegylated interferon- $\alpha$ and ribavirin therapy for chronic hepatitis C," Nature Genetics, vol. 41, no. 10, pp. 1105-1109, 2009.

[78] H. Ochi, T. Maekawa, H. Abe et al., "Il-28b predicts response to chronic hepatitis $\mathrm{C}$ therapy-fine-mapping and replication study in Asian populations," Journal of General Virology, vol. 92, no. 5, pp. 1071-1081, 2011.

[79] K. Ray, "Hepatitis: new gene IFNL4 is associated with impaired clearance of HCV," Nature Reviews Gastroenterology and Hepatology, vol. 10, no. 2, p. 63, 2013.

[80] O. J. Hamming, E. Terczyńska-Dyla, G. Vieyres et al., "Interferon lambda 4 signals via the IFN $\lambda$ receptor to regulate antiviral activity against $\mathrm{HCV}$ and coronaviruses," The EMBO Journal, vol. 32, no. 23, pp. 3055-3065, 2013.

[81] L. M. Real, K. Neukam, R. Herrero et al., "IFNL4 ss469415590 variant shows similar performance to rs12979860 as predictor of response to treatment against hepatitis $C$ virus genotype 1 or 4 in Caucasians," PLoS ONE, vol. 9, no. 4, Article ID e95515, 2014.

[82] H. Konishi, T. Motomura, Y. Matsumoto et al., "Interferonlambda4 genetic polymorphism is associated with the therapy response for hepatitis $\mathrm{C}$ virus recurrence after a living donor liver transplant," Journal of Viral Hepatitis, vol. 21, no. 6, pp. 397404, 2014

[83] S. Zeuzem, V. Soriano, T. Asselah et al., "Faldaprevir and deleobuvir for HCV genotype 1 infection," The New England Journal of Medicine, vol. 369, no. 7, pp. 630-639, 2013.

[84] S. Franco, E. Aparicio, M. Parera, B. Clotet, C. Tural, and M. A. Martinez, "IFNL4 ss469415590 variant is a better predictor than rs12979860 of pegylated interferon-alpha/ribavirin therapy failure in hepatitis C virus/HIV-1 coinfected patients," AIDS, vol. 28, no. 1, pp. 133-136, 2014.

[85] L. Covolo, S. Bibert, F. Donato et al., "The novel ss469415590 variant predicts virological response to therapy in patients with chronic hepatitis C virus type 1 infection," Alimentary Pharmacology \& Therapeutics, vol. 39, no. 3, pp. 322-330, 2014.

[86] S. Akkarathamrongsin, V. D. Thong, S. Payungporn et al., "IFNL3 (IL28B) and IFNL4 polymorphisms are associated with treatment response in Thai patients infected with HCV genotype 1, but not with genotypes 3 and 6," Journal of Medical Virology, vol. 86, no. 9, pp. 1482-1490, 2014. 


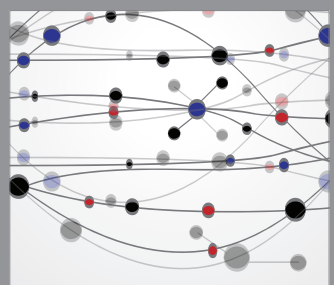

The Scientific World Journal
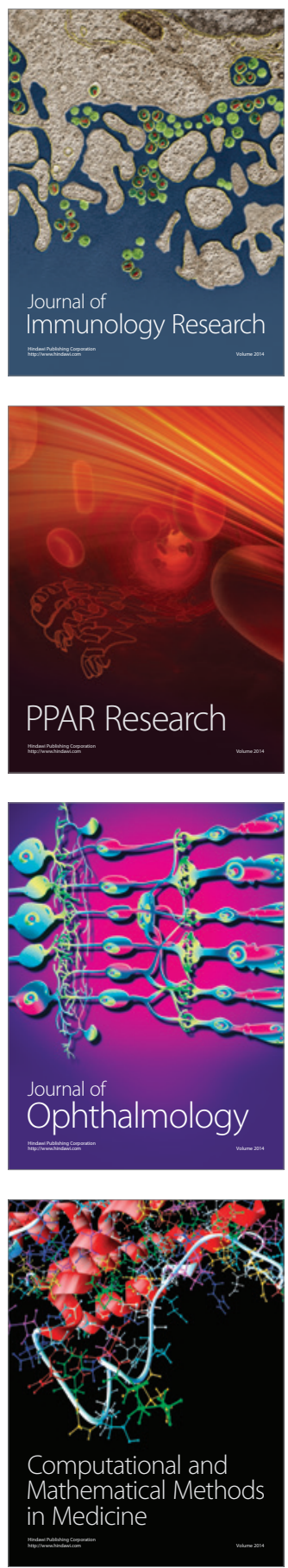

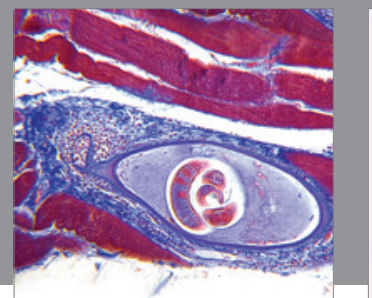

Gastroenterology

Research and Practice
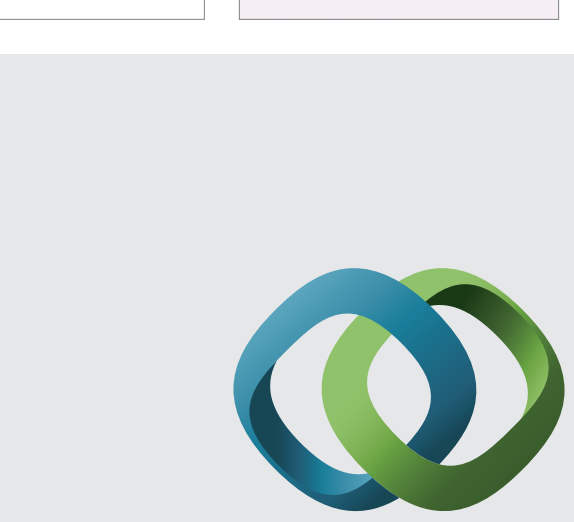

\section{Hindawi}

Submit your manuscripts at

http://www.hindawi.com
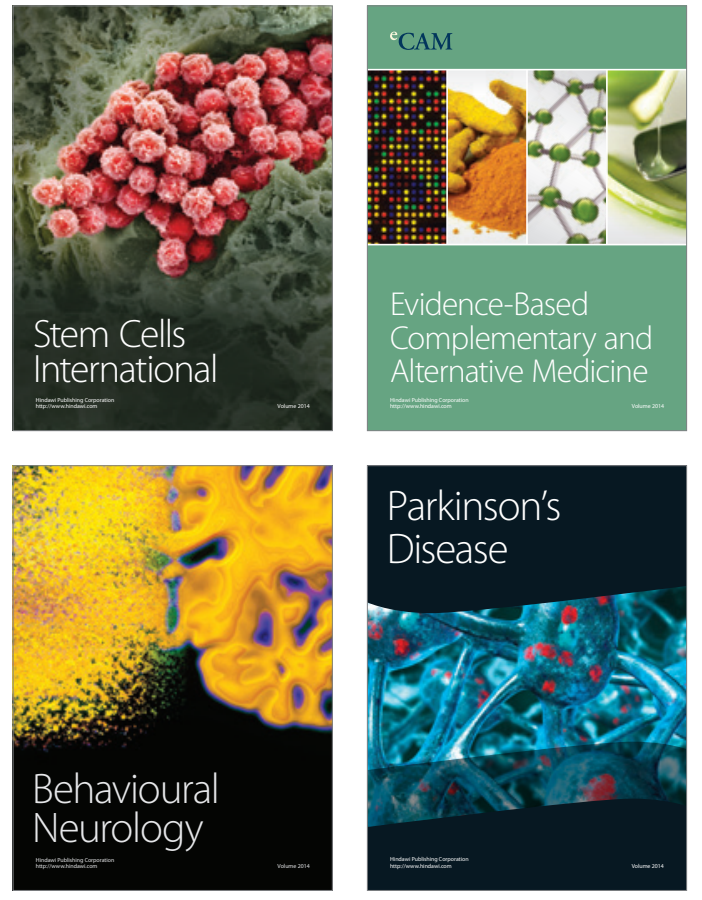
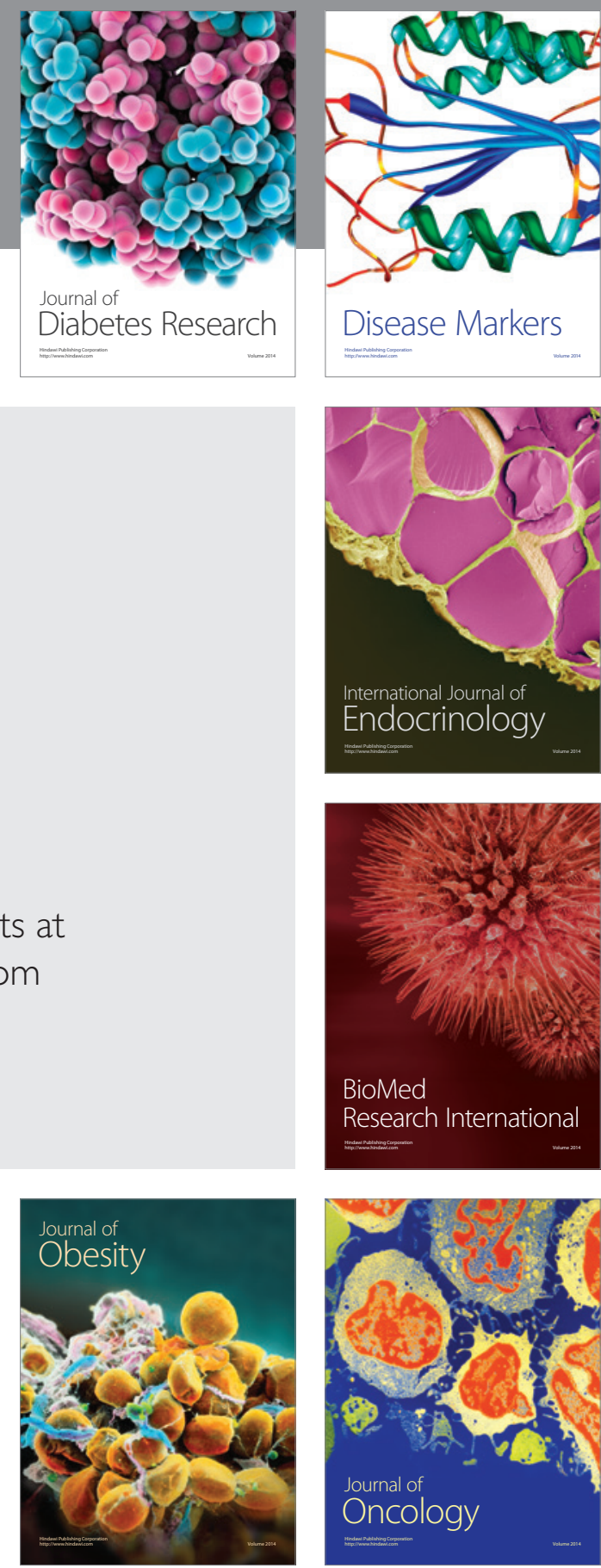

Disease Markers
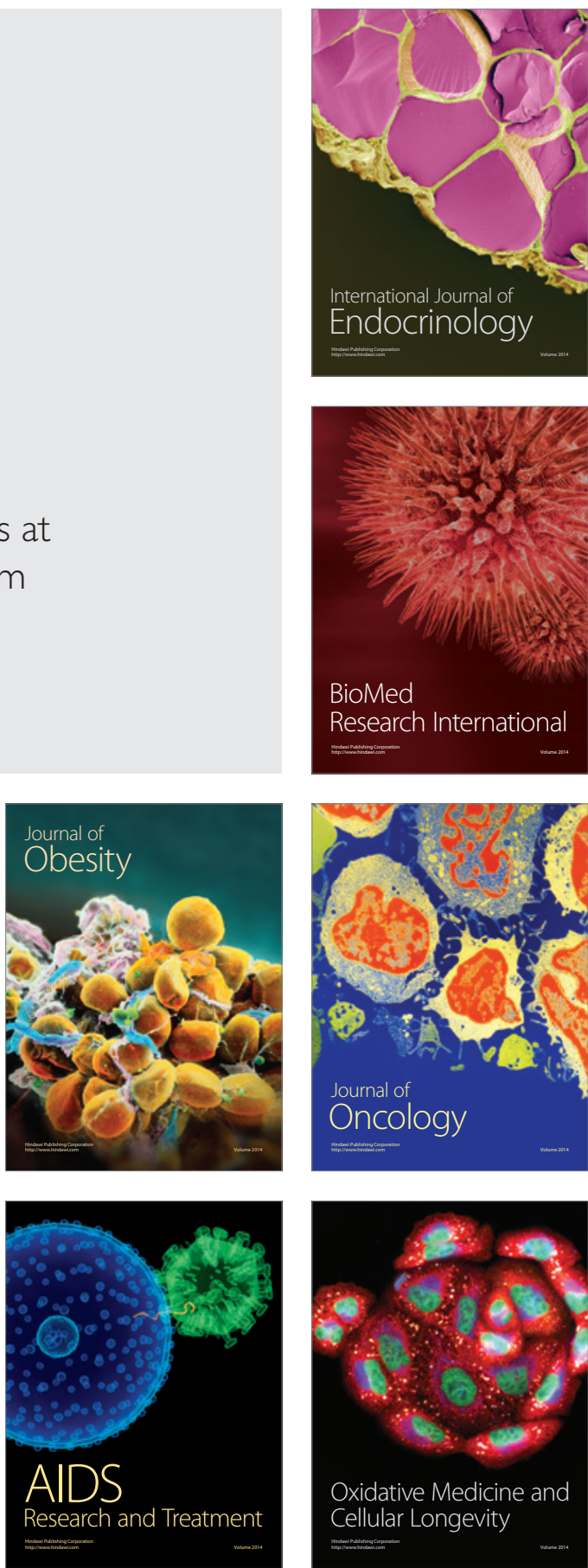